\title{
Webpage for Third Year Medical Students Pediatric Clerkship: Is Improved Access Information Useful and Educational?
}

\author{
Amy Guiot ${ }^{*}, 1$, Melissa Klein ${ }^{1}$, Chris Peltier ${ }^{1}$, Constance McAneney ${ }^{2}$ and Corinne Lehmann ${ }^{3}$ \\ ${ }^{I}$ Department of General and Community Pediatrics at Cincinnati Children's Hospital Medical Center in Cincinnati \\ Ohio, USA \\ ${ }^{2}$ Department of Emergency Medicine at Cincinnati Children's Hospital Medical Center in Cincinnati, Ohio and former \\ Director of Medical Student Education for the University of Cincinnati College of Medicine, USA \\ ${ }^{3}$ Department of Adolescent Medicine at Cincinnati Children's Hospital Medical Center and is the current Director of \\ the Pediatric Clerkship for the University of Cincinnati College of Medicine, USA
}

\begin{abstract}
Background: While many medical schools utilize webpages containing administrative information for students, this study evaluated a webpage that combines administrative and educational material in one convenient location.

Objective: 1) Assess need to create centralized webpage for third year medical students on their pediatric clerkship; 2)Design webpage with administrative and educational information; 3) Review webpage's usefulness.

Methods: Pre-test post-test survey with 5 point Likert and yes/no questions, created de novo on SurveyMonkey and emailed to medical students upon completion of their pediatric clerkship. Pre-intervention students used paper orientation packets. Pre-test survey addressed time to find resources and need for centralized location. Post-intervention students had access to new webpage with: 1) Fundamentals and Forms, 2) Orientation Information, 3) Key Resources, 4) Pediatric PowerPoint Presentations, 5) Journal Articles. Post-test questions regarded usefulness, relevance, accessibility, efficiency of webpage and perceived effect on knowledge-base.
\end{abstract}

Results: 49/72 (68\%) pre-intervention students responded to survey reporting accessing multiple internet sites for medical information, $95.9 \%$ used orientation handouts, $62.6 \%$ used resident webpage, $73.5 \%$ thought new webpage would be useful and $81.7 \%$ strongly agreed/agreed webpage would improve time efficiency. 32/72 (44\%) post-intervention students responded to survey. $100 \%$ post-intervention students used new webpage, $65.6 \%$ strongly agreed/agreed information was easily accessible, $68.8 \%$ found information relevant, $64.6 \%$ agreed easy to navigate, and $53.1 \%$ strongly agreed/agreed (7.4\% disagreed) readily available learning resources on website improved their pediatric knowledge.

Conclusion: The introduction of a webpage with administrative and educational materials for the pediatric clerkship was useful to majority of third year medical students.

Keywords: Medical student education, pediatic clerkship, webpage.

\section{INTRODUCTION}

Technology and computers have increasing importance and presence for medical students in both the classroom and hospital. Medical students use information technology in many ways, including web-based resource for core science courses [1] and hand held portable digital assistants (PDA) for both medical education and patient care [2]. According to the Association of American Medical Colleges (AAMC) 1998 Medical School Objective Project, educational technology is increasing rapidly in medical schools. They recommend that schools develop a strategic approach to accommodate their students' increasing technologic demands [3].

*Address correspondence to this author at the Pediatric Clerkship, Pediatric Hospitalist, General Inpatient Service, Director, Inpatient Community PhysicianTeaching Program, Cincinnati Children's Hospital Medical Center, USA; Tel: 513636 4198; Fax: 513636 7247;

E-mail: Amy.Guiot@cchmc.org
A new era is occurring with hospitals incorporating information technology into electronic health records including order entry, prescription orders, laboratory and radiology results. The internet has also become a new medical teaching tool with on-line journals, medical websites (eMedicine, Up To Date, etc.), and web-based computer cases (Computer Assisted Learning in Pediatrics Program (CLIPP) cases) [4]. The availability of easily accessible on-line search engines and resources provide a readily available web-based library for students who would previously have had limited access due to the time restraints of patient care activities during their clerkships [5].

Traditionally, educational and administrative information pertaining to the pediatric clerkship at our institution, like many, had been located in a variety of places including written hand-outs, textbooks, journals, and multiple computer websites. After observing medical students' use of hand held devices to look up medications and patient care information and recognizing that many medical students were forgetting important paperwork, such as feedback and observed history 
and physical exam forms, it seemed appropriate to utilize technology to improve the pediatric clerkship experience.

In the literature there are a limited number studies regarding use of comprehensive websites for third year medical students on their core clerkships. White et al. created "Medical Education on the Web" (MEOW) to maintain communication with off -campus students; five of seven core clerkships posted content to provide consistent information within the core clinical clerkship [6]. While they noted that their site contained "administrative guidelines, curriculum, goals, expectations, evaluation and feedback forms, Internet-based patient logs, and links to other websites," they did not address if the site affects students' experience or learning. Scarpace presented research regarding the utility of a website for pharmacy students at the American Association of Colleges of Pharmacy meeting [7]. They demonstrated that a web-based resource improved communication among the clinical team, provided resources to enhance student knowledge, and promoted independent study. Similar to White's publication, Scarpace's study did not elicit the students' opinions.

The purpose of this study was to determine baseline medical student usage of existing computer-based methods for learning and to assess the need for a newly designed website with educational and organizational information and gather information on the design of this newly created centralized webpage. Education experts designed a webpage to improve access to administrative and educational information (orientation packet, hospital clinical guidelines, PowerPoint presentations, links to search engines, pertinent articles, and CLIPP cases). In order to evaluate the newly created webpage, the medical students' utilization of the new webpage was measured as well as their opinions of time efficiency and any perceived effects on knowledge.

\section{METHODS}

This study used a pre-test and post-test survey completed by third year medical students after finishing their pediatric clerkship. The study was approved by the Institutional Review Board of Cincinnati Children's Hospital Medical Center (CCHMC).

\section{Study Setting}

Third year medical students from the University of Cincinnati College of Medicine participate in an eight week pediatric clerkship at CCHMC, a large, urban, academic, pediatric medical center with 490 inpatient beds. Approximately 25 students rotate through the pediatric clerkship every two months, each spending four weeks on the inpatient service and four weeks in an outpatient experience. The outpatient month combines a variety of experiences in the pediatric emergency department, an off campus newborn nursery, and a primary care experience in either the hospital based primary care center, off site community health center, or private practices.

\section{Study Subjects}

The pre-intervention subjects were third year medical students on their pediatric clerkship from January 2009 through June 2009 prior to the implementation of the medical student website. The post-intervention subjects were third year medical students on their pediatric clerkship from January 2010 through June 2010 after the implementation of the medical student website.

\section{Study Design}

Pre-intervention surveys were administered to medical students who completed their clerkship from January 2009 through June 2009. After student focus groups, a centralized webpage was designed during the period June through October 2009. The webpage was launched January 2, 2010. The post-intervention surveys were administered January 2010 through June 2010, during the same six month time period of the successive year. Both survey groups received the survey invitation three times via email to encourage completion. Students could only complete the survey once. To examine the impact of a centralized webpage on student learning, aggregate Shelf Exam scores were accessed in an anonymous manner for both groups. During the study, there were no other substantive changes in the didactics presented in the clerkship.

\section{Survey Development}

Two surveys were developed de novo by consensus of an interdisciplinary group of medical educators from the General Pediatrics Education section and the Medical Education Research Group. Both surveys contained answer responses based on a 5 point Likert scale (strongly agree, agree, neutral, disagree, strongly disagree) in addition to yes/no and multiple response type questions. The pre-intervention questions focused on the 1) usefulness of content on the resident homepage, 2) frequency of student use of the resident homepage, 3) where the students located administrative and educational information and 4) ease of access to educational resources. The post-intervention questions addressed 1) relevance of the new webpage's material, 2) accessibility to the webpage, 3) ease of use, and 4) perceived effects on knowledge. Both surveys asked about use of existing computerbased learning. Both surveys were anonymous, voluntary, and distributed via an Internet survey platform (www.surveymonkey.com) and distributed via email which contained a link to the survey.

\section{Webpage Development}

Near the end of the pre-intervention time period in 2009, a focus group of third year medical students was convened regarding the development of a new medical student webpage. Three of the authors, who are medical student and pediatric resident educators, lead the focus group which was composed of approximately twelve volunteer medical students. The medical students finishing their pediatric clerkship in the spring of 2009 were sent an email requesting their voluntary presence at a meeting to discuss a possible medical student webpage. The students were asked to share their opinions of usefulness of a medical student webpage, appropriate content, and design. After consideration of the medical student input, the pediatric clerkship director, a variety of pediatric subspecialties, and the medical student coordinator in conjunction with the institution's medical educational and information technology experts, discussed, planned and implemented this new webpage.

Our institution already developed a webpage platform for general use in the hospital called Centerlink. It contains a 


\begin{tabular}{|c|c|}
\hline \multicolumn{2}{|c|}{ Fundamentals and Forms } \\
\hline contacts & Pagers \\
\hline Bedside Clinical Exercise & patientlog \\
\hline cCHMc Dress code & ppC Feedback Form \\
\hline CLIPP Cases & PPC Master Schedule \\
\hline Grand Rounds & Problem Sets for Third Year Clerkship in Pediatrics \\
\hline Home Health Care Visit & Procedure Requirements for Pediatrics \\
\hline LCME Duty Hours \& Rules & Resident Conference Schedule \\
\hline Mid-Rotation Feedback Form & student Schedule \\
\hline Morning Report & Inpatient student Schedule \\
\hline
\end{tabular}

\section{Checkllss}

Curriculum for Third-Year Clerkship in Pestiatrics

Detailed History \& Physical Sample

Grading Guidelines

Geals and Objectives

Inpartent Pedlatric Clerkship Orientation

Qutpatient Pediatrics Orientation

Orientotion to PPC

Procedure Requircments for Pediatric

Pediatric Clerkship Orientation

Sample SOAP Note

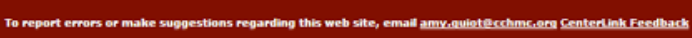

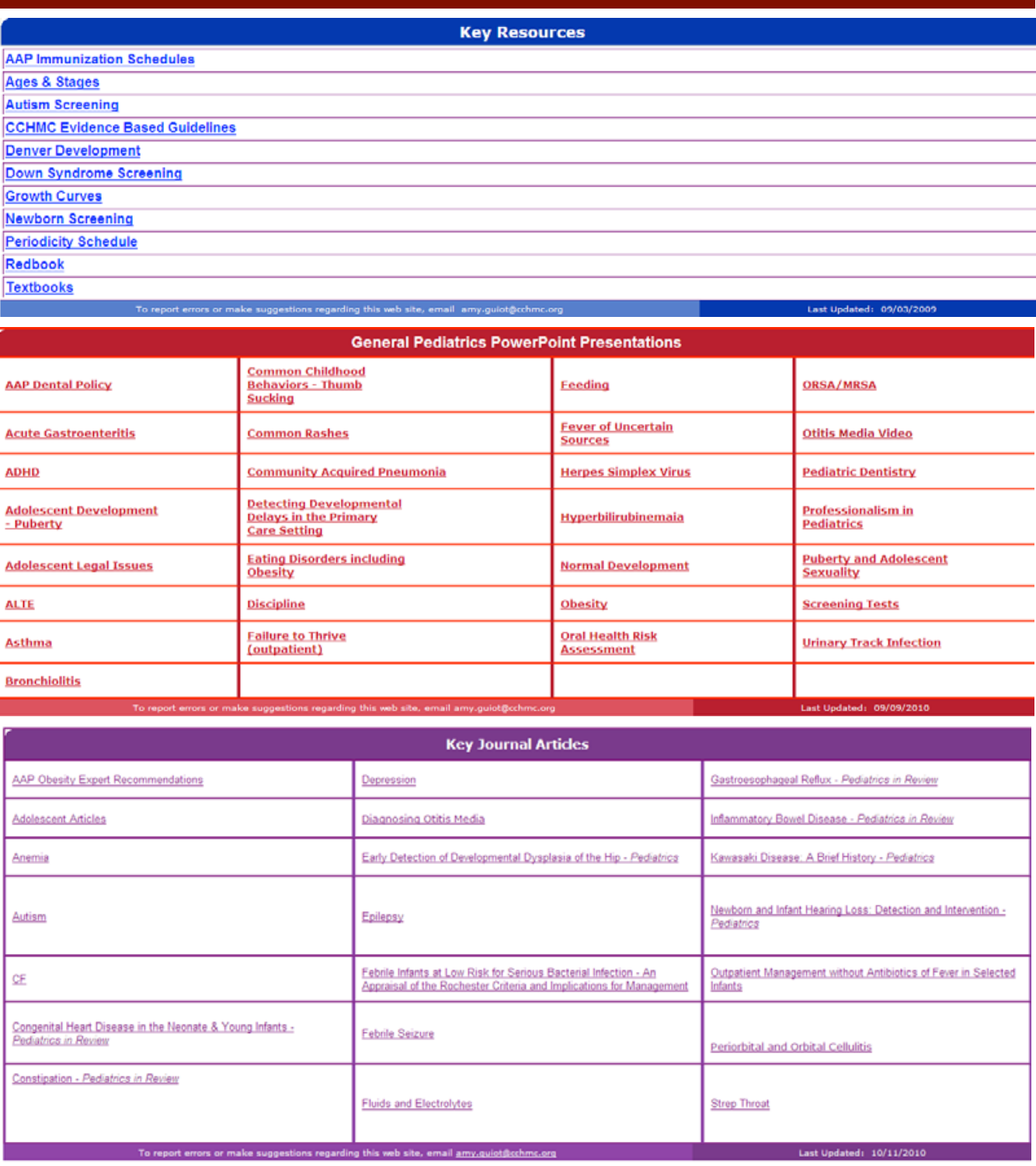

Fig. (1). Medical Student Web Page Image on hospital website. 
variety of homepages for different users (medical staff, general employees, residents, etc.). The residents' homepage links to their schedules, goals and objectives of rotations, the hospital electronic medical record, journals, treatment guidelines, etc. Since medical students reported in the pilot group to routinely visit the resident homepage looking for information, the new medical student webpage was placed on the resident homepage.

The webpage was then designed to contain materials grouped into five main topic headings: 1) Fundamentals and Forms, 2) Orientation Information, 3) Key Resources, 4) General Pediatric Power Point Presentations, and 5) Key Journal Articles. (See Fig. 1) Within each topic heading, there were multiple links that the student could access. The Fundamentals and Forms section provides schedules, policies, required forms, and learning goals and objectives. The Orientation Information section has presentations from orientation, lists of learning requirements, grading guidelines, and an overview of the clerkship curriculum. The Key Resources section has links to nationally recognized evidencebased patient care resources, such as the ACIP immunization schedule, developmental milestone guidelines, the Redbook, and various screening recommendations. The General Pediatric Power Point Presentation section has a number of core inpatient and outpatient general pediatric resident presentations modified for student education. Key Journal Articles contain good review articles recommended by pediatric generalists and subspecialists at our institution.

Once the new webpage was created, medical students had access to educational and organizational information from any computer at the hospital or from home via the hospital website. Since it was unknown if the students would use the new webpage, students in both the pre and post-intervention groups continued to receive the paper versions of the orientation information during their formal orientation to the pediatric clerkship.

\section{RESULTS}

\section{Student Demographics}

The 2009 third year medical student class (preintervention group) was composed of a total of 166 students, $54 \%$ males and $46 \%$ females witha total of $6 \%$ underrepresented minorities (African American, Native American, Mainland Puerto Rican, or Mexican American) [8]. Seventyfour students rotated through pediatrics January 2009 through June 2009. The 2010 third year medical student class (post-intervention group) was composed of a total of 170 students, $51 \%$ male and $49 \%$ females with a total of $12 \%$ under-represented minorities. Seventy-five students rotated through pediatrics January 2010 through June 2010.

\section{Survey Completion}

The 2009 pre-intervention survey was completed by $49 /$ $74(66 \%)$ of subjects. The 2010 post-intervention survey was completed by $32 / 75$ (43\%).

\section{Pre- Intervention Survey Results}

1. Current computer-based learning resource use: For the pre-intervention third year medical students responses, 96\% used the pediatric resident homepage on Centerlink: $43.8 \%$ used it $1-5$ times per day, $18.8 \%$ greater than 5 times per day, and the remaining $37 \%$ once per day or less. Students reported accessing the internet for a variety of resources (see Table $\mathbf{1}$ ).

Table 1. Variety of Sources Used by Pre-Intervention Medical Students for Educational and Organizational Information

\begin{tabular}{|c|c|}
\hline Sources of Information & $\begin{array}{c}\text { \% pre-intervention students } \\
\text { reported use }\end{array}$ \\
\hline \hline CHMC guidelines & $81.6 \%$ \\
\hline Search engines (Yahoo, Google) & $46.9 \%$ \\
\hline Websites (AAP, CDC) & $98 \%$ \\
\hline Journal Articles & $42.9 \%$ \\
\hline Textbooks & $49 \%$ \\
\hline Paper orientation handouts & $95.6 \%$ \\
\hline
\end{tabular}

2. Student thoughts regarding a centralized student webpage: $73.5 \%$ of pre-intervention medical students responded that a medical student link on the resident tab on Centerlink which contained administrative and clinical information in one place would be helpful; $18.4 \%$ were neutral, only $8.2 \%$ did not think it would be useful. Additionally, $81.7 \%$ of the students felt that they could more effectively spend their time if an easily accessible website containing both administrative and medical knowledge resource existed.

\section{Post Intervention Results}

1. Current Computer-Based Learning Resource Use; $100 \%$ of the medical students used the pediatric resident homepage on Centerlink; $6.3 \%$ used it greater than 5 times per day, $34.4 \%$ used it $1-5$ times per day, $46.9 \%$ of students used it greater than twice per week but less than daily and $12.5 \%$ less than once per week.

2. Students' opinions regarding the centralized student website are presented in Table $\mathbf{2}$.

Table 2. Post-Intervention Students' Opinions of Website

\begin{tabular}{|c|c|c|}
\hline & $\begin{array}{c}\text { \% of students } \\
\text { Agree/Strongly } \\
\text { Agree }\end{array}$ & $\begin{array}{c}\text { \% of students } \\
\text { Disagree/Strongly } \\
\text { Disagree }\end{array}$ \\
\hline \hline Relevance & $68.8 \%$ & $12.5 \%$ \\
\hline Accessibility & $65.6 \%$ & $15.7 \%$ \\
\hline Ease of Navigation & $64.6 \%$ & $9.7 \%$ \\
\hline $\begin{array}{c}\text { Perceived improvement } \\
\text { in knowledge }\end{array}$ & $53.1 \%$ & $9.4 \%$ \\
\hline
\end{tabular}

In addition, $81.3 \%$ of students strongly agreed/ agreed that they were more likely to read a journal article or view a PowerPoint presentation if it was easily accessed.

3. Shelf Exam Scores: The mean pre-interventions medical students' shelf exam score was 82.8 , compared to the 
mean score for the post-intervention group which was $84.1(\mathrm{P}=0.54)$

\section{DISCUSSION}

This study evaluated third year medical students' opinion of a webpage specifically designed to incorporate both administrative and educational material in one convenient location. The majority of these medical students found the webpage useful, relevant, accessible, and easy to navigate and perceived that it helped improve their knowledge.

Medical students' utilization of information technology for patient care and education has increased and become part of their daily routine. The medical education literature reveals that medical students use online resources ( $U p$ to Date, MD Consult, and MEDLINE) as opposed to textbooks, especially related to patient treatment plans $[9,10]$.Since contemporary medical students are skilled in computer and internet technologies [11], it seemed appropriate to use the computer as a tool to provide an easily accessible location for the clerkship and educational materials. Our purpose in developing a medical student webpage for the pediatric clerkship was to provide a centralized site with readily available administrative and educational resources.

Prior to the creation of the medical student webpage, students utilized various websites to search for medical information. For example, in order to access relevant articles, students needed to navigate through several links on the resident homepage or perform a web search. Additionally, clerkship administrative information was delivered as handouts requiring medical students to carry a cumbersome orientation packet which was often left behind elsewhere.

A majority of the pre-intervention third year medical students felt that access to a central computer repository, for both educational and administrative information would be beneficial and improve their efficiency. This is consistent with other published studies. Mooney and Bligh's found that the internet can present valuable opportunities to support medical education [12]. White et al. MEOW [6] was an exciting first step in the investigation of an on-line medical student website; however, our study takes the data one step further by demonstrating medical student use and opinions of the site and that the majority of students found the webpage accessible, relevant, and easy to navigate, which they felt could improve their pediatric knowledge. DeGroote et al also found that online resources are preferred due to the convenience [13].

While the students were using our institutional resident homepage at a high rate in both the pre and post-intervention groups, there was less frequent daily use in the postintervention group. This could represent an increase in their efficiency in finding desired resources on the newly created webpage as almost two-thirds of the post-intervention group surveyed found the new page easy to access and navigate.

A large majority of students also felt they were more likely to read a journal article or view a PowerPoint presentation if it were easy to access. In the evolving era of multiple demands on faculty teaching and clinical time, effective computer-based teaching methods will continue to be sought as a means to fill teaching gaps. About half of our students felt the available web resources presented improved their pediatric knowledge. While not statistically significant, there appeared to be a trend in increased Shelf Exam scores in the post-intervention group.

Of note, our institution had a functional website that was available to us at no cost. While most institutions have websites, they may not be as accessible for easily posting medical student educational resources. There was also a wealth of materials previously developed that were easily uploaded to the website. Creating these materials from scratch and maintaining them can take significant faculty time.

Medical students in our study demonstrated a high use of a centralized webpage for learning, indicating this is a viable platform for teaching and learning. Our institution is engaging in ongoing efforts to improve the webpage, including maintenance of current guidelines and articles, functionality, and dissemination to our own faculty of the site's existence. While it appears the time of computer-based teaching is here and is accepted by medical students, further study is needed in the field of pediatrics to demonstrate the long-lasting educational and patient care impact of these methods.

This student webpage study was unique compared to other studies because the webpage combined both administrative and educational material whereas other studies focused only on administrative topics. In addition, this is the first study to actually survey the medical student's opinions regarding the webpage as opposed to simply sharing information regarding the content of the webpage.

This study has several limitations. First, it was designed to have the surveys e-mailed immediately following completion of the eight week clerkship, which occurred for the 2009 pre-intervention group. However, the 2010 post-intervention group's survey was e-mailed as a group in July 2010, between one and five months after completion of the clerkship, which may have influenced the number and the quality of the responses, possibly accounting for the larger number of neutral answers in the post-intervention group. This study was performed on third year medical students at a single medical center during their pediatric rotation, so the results may not be generalizable to other institutions. Although we believe the information can be transferrable to other institutions, we did not study this.And finally, this study did not directly measure knowledge or patient care differences.

\section{CONCLUSIONS}

The medical student webpage, combining administrative and educational materials for the pediatric clerkship, was considered useful, accessible, relevant and easy to navigate by the majority of the students. Since the educational material was previously created by faculty, the time required to organize and upload to the webpage was considered minimal and worthwhile. While administrative information varies between medical schools, PowerPoint presentations and recommended journal articles can be universal, thus, worth sharing among institutions. Future studies could involve distributing educational topics among institutions to upload on their webpages and determine changes in usage of their webpages, which, ultimately, could impact medical student knowledge base to effect changes of patient care due to the readily accessible information. 


\section{CONFLICT OF INTEREST}

None declared.

\section{ACKNOWLEDGEMENT}

The authors would like to acknowledge Dr. Ray Baker and Joyce Salter for all their assistance with this project.

\section{REFERENCES}

[1] Nieder GL, Nagy F. Analysis of medical students' use of Webbased resources for a gross anatomy and embryology course. Clin Anat 2002; 15: 409-18.

[2] Kho A, Henderson LE, Dressler DD, Kripalani S. Use of handheld computers in medical education. J Genl Int Med 2006; 21: 531-7.

[3] Moberg T, Whitcomb M. Educational technology to facilitate medical students learnings: background paper 2 of the medical student objectives project. Acad Med 1999; 74: 1146-50

[4] Leong S, Baldwin C, Adelman A. Integrating web-based computer cases into a required clerkship: development and evaluation. Acad Med 2003; 78: 295-301.

[5] Tannery et al. Use of Web-based Library resources by medical students in community and ambulatory settings. J Med Library Assoc 2002; 90: 305-9.
[6] White B, Albritton T, Rindt K. MEOW: a web site to improve consistency and communication in clerkships. Acad Med 2001.

[7] Scarpace S. "Utility of a website to improve the clerkship experience and enhance clinical team collaboration." Paper presented at the annual meeting of the American Association of Colleges of Pharmacy, Sheraton, San Diego Hotel and Marina, San Diego, California, July 2006

[8] AAMC. Discussion Document and Alternative Policy Option: Review of the Definition of "Under-represented Minorities", 2002 Web Document AAMC website http://www.med.uc.edu/ admissions.

[9] Peterson M, Rowat J, Kreiter C. Mandel L. Medical students' use of information resources: is the digital age dawning? Acad Med 2004 79: 89-95

[10] Cogdill KW, Moore ME. First-year medical students' information needs and resource selection: responses to a clinical scenario. Bull Med Libr Assoc 1997; 85: 51-4.

[11] Sandars J, Shroter S. Web 2.0 technologies for undergraduate and postgraduate medical education: an online survey. Postgrad Med J 2007; 83: 759-62.

[12] Mooney GA, Bligh JG. Information technology in medical education: current and future applications. Postgrad Med J. 1997; 73: 701-4.

[13] De Groote SL, Dorsch JL. Measuring use patterns of online journals and databases. J Med Libr Assoc 2003; 91: 231-40.

(C) Guiot et al.; Licensee Bentham Open

This is an open access article licensed under the terms of the Creative Commons Attribution Non-Commercial License (http://creativecommons.org/licenses/by-nc/3.0/) which permits unrestricted, non-commercial use, distribution and reproduction in any medium, provided the work is properly cited. 